\title{
Assessment of the Malaysian tidal stream energy resource using an upper bound approach
}

\author{
Paul A. J. Bonar ${ }^{1} \cdot$ Andrea M. Schnabl $^{1} \cdot$ Wei-Koon Lee ${ }^{2} \cdot$ Thomas A. A. Adcock $^{1}$ (1)
}

Received: 27 June 2017 / Accepted: 15 January 2018 / Published online: 2 February 2018

(c) The Author(s) 2018. This article is an open access publication

\begin{abstract}
In this paper, an upper bound approach is used to determine the maximum power available to tidal stream turbines placed at five sites along the west coast of Peninsular Malaysia. A depth-averaged hydrodynamic model of the Malacca Strait is built and validated against field measurements. Actuator disc theory is then used to introduce rows of tidal stream turbines as line sinks of momentum and to determine the maximum time-averaged power available to rows of both moderately sized and very large turbines, placed strategically at the locations of highest naturally occurring kinetic energy flux. Results suggest that although the Malaysian tidal stream energy resource is not large enough to make a significant contribution to the country's energy mix, there may yet be opportunities to use low-speed tidal turbines in small-scale and off-grid electricity generation schemes. Methods are described in detail and links to source codes and results are provided to encourage the application of this simple, yet effective resource assessment methodology to other promising tidal energy sites.
\end{abstract}

Keywords Tidal stream $\cdot$ Power $\cdot$ Energy $\cdot$ Resource assessment $\cdot$ Malacca Strait $\cdot$ Malaysia

\section{Introduction}

Southeast Asian countries are facing a 'trilemma' - the need to deliver on energy security, economic growth, and development in a sustainable way (Low 2012; Quirapas et al. 2015). In response to changing climates, fossil fuel producing countries like Malaysia are looking increasingly to renewable and sustainable energy sources and particularly those that can be used in rural electrification (Petinrin and Shaaban 2015). A number of authors have suggested that tidal stream energy could be an attractive prospect for Malaysia (e.g. Lim and Koh 2010; Sakmani et al. 2013; Bohari et al. 2016), but as of yet there has been no robust assessment of the available power.

Tidal stream energy resources may be assessed using different approaches. One of the earliest of these involved estimating the extractable power as some fraction of the naturally occurring kinetic energy flux. This approach has

Thomas A. A. Adcock

thomas.adcock@eng.ox.ac.uk

1 Department of Engineering Science, University of Oxford, Parks Road, Oxford OX1 3PJ, UK

2 Faculty of Civil Engineering, Universiti Teknologi MARA, 40450 Shah Alam, Selangor, Malaysia since been shown to be inaccurate, however, because it does not account for the fact that the presence of turbines will alter the natural kinetic energy flux (Garrett and Cummins 2005, 2008). Tidal stream energy resources are now typically assessed by introducing additional sources of resistance, often in the form of patches of enhanced bed roughness (e.g. Divett et al. 2013; Funke et al. 2014), into numerical models to calculate the maximum extractable power. One promising alternative is the upper bound approach developed by Adcock et al. (2013), which uses a sub-grid-scale actuator disc model to introduce rows of tidal turbines as line sinks of momentum (Houlsby et al. 2008; Draper et al. 2010). This approach provides a simple means by which to establish an upper bound on the power available to rows placed at a given location and also enables comparison, in terms of power per swept area, between different development options.

In the present study, the upper bound approach of Adcock et al. (2013) is used to assess the tidal stream energy resources of a number of candidate sites in Malaysia. The study focuses on the Malacca Strait, which appears to offer the most favourable coastal geometry and electrical infrastructure for tidal stream power development. A depth-averaged hydrodynamic model of the region is built, validated, and modified to include rows of tidal stream turbines at five sites along the Malaysian coastline. This model is then used to assess 
the maximum time-averaged power available to rows of both moderately sized and very large turbines at each site, and to highlight practical considerations such as the temporal variations in available power and the associated changes to the natural flow regime. The primary motivation for this work is to determine whether or not tidal stream power can make a significant contribution to the Malaysian energy mix. An important secondary motivation is to explain clearly how this upper bound approach works and to make available the source codes to encourage its application to other promising tidal energy sites.

\section{Model}

\subsection{Numerical scheme}

Tidal flows are simulated by using the discontinuous Galerkin (DG) version of the open source hydrodynamic model ADCIRC (ADvanced CIRCulation model) (Kubatko et al. 2006, 2009) to solve the shallow water equations. These equations have long been the model of choice for tidal hydrodynamics and, despite their simplifying assumptions, are known to be able to capture accurately the bulk flow through channels and around headlands that is most important in determining the available power (Adcock et al. 2015).

The DG ADCIRC code has been modified by Serhadlıoğlu (2014), following Draper et al. (2010) and Draper (2011), to incorporate the open channel actuator disc model of Houlsby et al. (2008) at sub-grid scale. This modification allows idealised representations of tidal turbines, defined by a local blockage ratio $B$ and local wake velocity coefficient $\alpha_{4}$, to be placed between adjacent elements in the numerical mesh. As flow passes through these turbines, the actuator disc model calculates the available power and alters the momentum of the flow by imposing the corresponding head drop as a discontinuous change in fluid depth (Draper et al. 2010). The available power is defined herein as the amount remaining when the power dissipated in wake mixing downstream of the turbines is subtracted from the total amount of power extracted from the flow (Adcock et al. 2013). Given that this measure does not account for additional losses due to, for instance, nonuniform inflow profiles, the drag on turbine support structures, or generation inefficiencies, it therefore represents an upper bound on the power that would be available to real turbines.

This line sink representation greatly simplifies the modelling of tidal turbines, which can be introduced using only two parameters $\left(B\right.$ and $\left.\alpha_{4}\right)$ and without having to describe their structure or approximate the highly threedimensional local mixing processes. Naturally, this representation requires some additional assumptions-the most obvious being that local-scale mixing lengths must be small compared to the size of the elements and that the flow must change sufficiently slowly as to be considered quasi-steady (Draper et al. 2010)—but it has been compared favourably with laboratory-scale physical experiments (Draper et al. 2013) and used to determine the maximum power available to rows of turbines placed at a number of promising sites in the UK (e.g. Adcock et al. 2013; Serhadlıoglu et al. 2013). The upper bound approach of Adcock et al. (2013) uses this line sink representation to improve on previous resource assessment methodologies by comparing different development options in terms of the maximum time-averaged available power per swept area of turbine. This is a particularly useful metric, which may also be used to find the most productive location for a row of tidal turbines and to compare its projected performance with that of an alternative development, such as an offshore wind farm.

\subsection{Model details}

A review of the relevant literature reveals that the average current velocity in Malaysian waters is $\sim 1 \mathrm{~m} / \mathrm{s}$ (e.g. Hassan et al. 2012), which is generally considered too low to make for a viable tidal stream power development, but that velocities exceeding $1.5 \mathrm{~m} / \mathrm{s}$ have been reported at certain locations (United Kingdom Hydrographic Office 2006; United States National Geospatial Intelligence Agency 2016). The present study focuses on the Malacca Strait, which lies between the west coast of Peninsular Malaysia and the east coast of the Indonesian island of Sumatra (Fig. 1). This strait appears to offer the most favourable coastal geometry and electrical infrastructure for tidal stream power development and incorporates a number of sites, including Pangkor Island and Port Klang, which have been previously identified as potentially viable (Lee and Seng 2009; Sakmani et al. 2013).

The Malacca Strait is the main channel of exchange between the Indian Ocean and the South China Sea (United Kingdom Hydrographic Office 2006; United States National Geospatial Intelligence Agency 2016) and one of the world's most important shipping lanes (Kamaruzaman 1998; Khalid 2009). It is also known to have a particularly complex flow regime, with irregular and variable bathymetry (United Kingdom Hydrographic Office 2006; United States National Geospatial Intelligence Agency 2016); a mixed, but predominantly semidiurnal tidal system supplemented by a residual northwest-directed current (Wyrtki 1961; United Kingdom Hydrographic Office 2006; United States National Geospatial Intelligence Agency 2016); and circulation modulated by seasonal monsoon and tropical storm forcing (Rizal et al. 2012; Chen et al. 2014). This complexity, when combined with relatively few previous studies (e.g. Rizal and Sündermann 1994; Rizal et al. 2012; Chen et al. 2014) and a lack of high quality source and validation data, makes modelling the region especially difficult (Rizal et al. 2012). In the present 
Fig. 1 (Online version in colour.) Model domain and numerical mesh with contours of bathymetric depth superimposed on a NASA map provided by Bing. The positions of the water level and current velocity prediction stations are marked with white and black filled dots, respectively

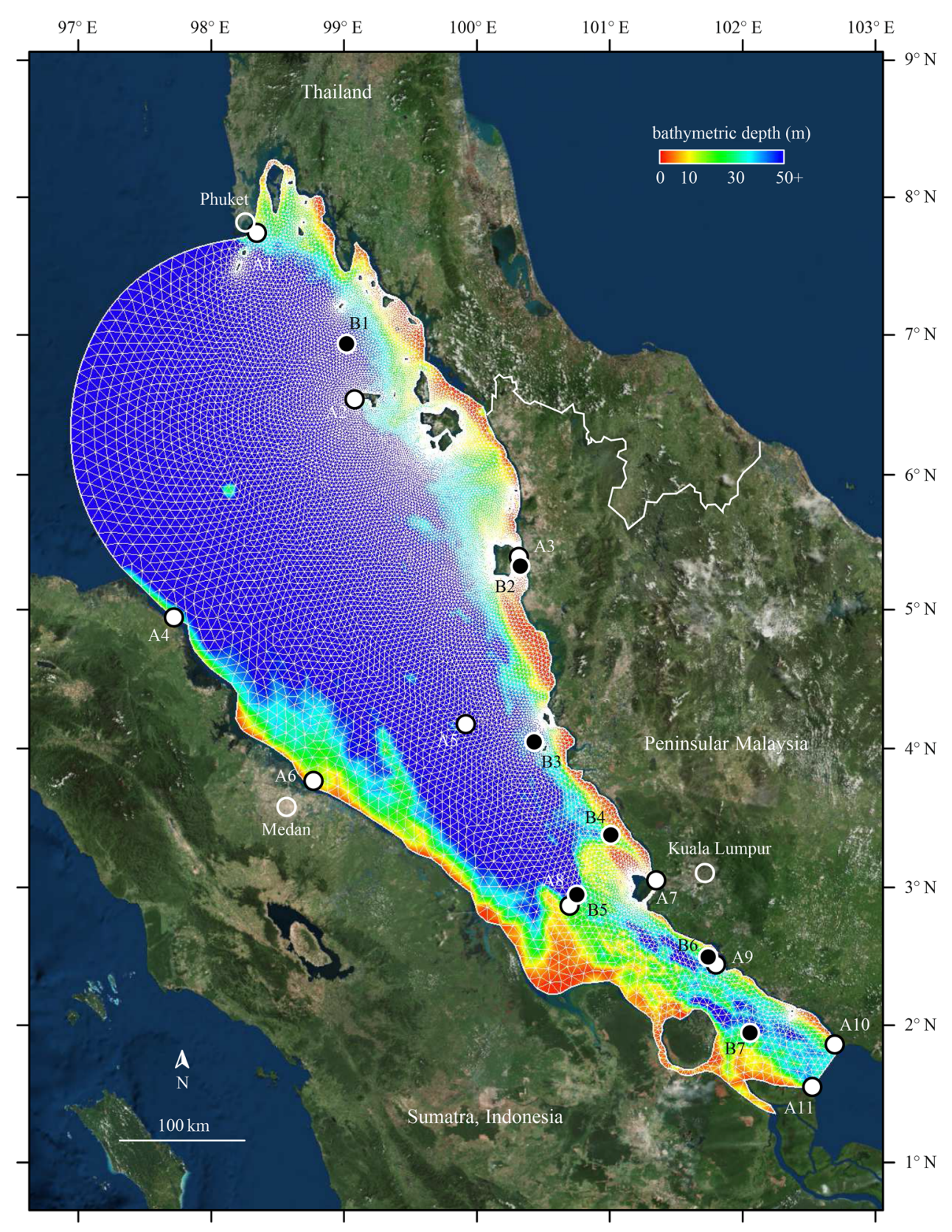

scoping study, however, the aim is simply to provide upper bound estimates of the tidal stream energy resource. The focus, therefore, is on capturing only the dominant physics of the system.

The model domain covers most of the Malacca Strait, extending from the Andaman Sea near the northern tip of Sumatra to the narrowest part of the strait at the Malaysian state of Johor. It is $\sim 840 \mathrm{~km}$ long and widens from $\sim 36 \mathrm{~km}$ at the eastern flow boundary, at which the average depth is $\sim 35 \mathrm{~m}$, to $\sim 290 \mathrm{~km}$ at the western flow boundary, at which the average depth is $\sim 700 \mathrm{~m}$ (Fig. 1). Placing an open flow boundary in shallow water is known to introduce numerical errors, particularly when the boundary is close to a site of interest (Garrett and Greenberg 1977), but, given the relatively small tidal stream power developments considered in the present study, it is expected that the errors introduced by placing the boundary within the strait would be small compared to those that would be introduced by extending the depth-averaged domain to include the extremely complex and much more three-dimensional tidal system between Singapore and Indonesia.

Bathymetry data are obtained from the GEBCO (GEneral Bathymetric Chart of the Oceans) 30 arc-second global grid and manually refined around the Malaysian coastline to give approximate visual agreement with British Admiralty charts. To improve model stability and simplify computation, 
Table 1 Predicted and modelled water level amplitudes (m)

\begin{tabular}{llllllc}
\hline Station & M2 (predicted) & M2 (modelled) & Error $(\%)$ & S2 (predicted) & S2 (modelled) & Error (\%) \\
\hline A1 & 0.804 & 0.807 & +0.4 & 0.472 & 0.381 & -24.0 \\
A2 & 0.700 & 0.686 & -2.1 & 0.401 & 0.364 & -10.3 \\
A3 & 0.637 & 0.614 & -3.8 & 0.426 & 0.392 & -8.7 \\
A4 & 0.472 & 0.610 & +22.6 & 0.282 & 0.315 & +10.4 \\
A5 & 0.612 & 0.776 & +21.2 & 0.349 & 0.317 & -10.0 \\
A6 & 0.603 & 0.593 & -1.7 & 0.343 & 0.325 & -5.4 \\
A7 & 1.390 & 1.360 & -2.2 & 0.799 & 0.655 & -21.9 \\
A8 & 1.300 & 1.319 & +1.5 & 0.716 & 0.591 & -21.0 \\
A9 & 0.845 & 0.783 & -7.9 & 0.483 & 0.543 & +11.1 \\
A10 & 0.645 & 0.602 & -7.2 & 0.333 & 0.091 & -266.2 \\
A11 & 0.723 & 0.651 & -11.1 & 0.382 & 0.071 & -437.0 \\
\hline
\end{tabular}

Table 2 Relative phases of predicted and modelled water level signals (degrees)

\begin{tabular}{lllllll}
\hline Station & M2 (predicted) & M2 (modelled) & Error $\left(^{\circ}\right)$ & S2 (predicted) & S2 (modelled) & Error $\left(^{\circ}\right.$ ) \\
\hline A1-A2 & -9 & -12 & -3 & -23 & -14 & +9 \\
A2-A3 & +287 & +311 & +24 & +300 & +318 & +18 \\
A3-A4 & -291 & -312 & -21 & -302 & -317 & -14 \\
A4-A5 & +230 & +231 & +1 & +237 & +240 & +3 \\
A5-A6 & +49 & +51 & +2 & +52 & +56 & +4 \\
A6-A7 & -118 & -100 & +18 & -124 & -126 & -2 \\
A7-A8 & +14 & +18 & +4 & +14 & +24 & +10 \\
A8-A9 & -49 & -55 & -6 & -50 & -48 & +2 \\
A9-A10 & -79 & -93 & -14 & -79 & -53 & +26 \\
A10-A11 & +22 & -8 & -30 & +25 & -38 & -63 \\
\hline
\end{tabular}

the coastlines are smoothed, a number of small islands and channels are removed, and wetting and drying is neglected. The numerical mesh is initially unstructured, with $\sim 28,000$ elements varying in length from $\sim 320 \mathrm{~m}$ around the sites of interest to $\sim 11 \mathrm{~km}$ at the western flow boundary. The model is tested with three different meshes and time steps and the resulting surface elevations and velocities are compared at four locations along the centreline of the channel. Results from these tests show that although there are some variations in the shallow regions, the model solutions are reasonably mesh and time step independent.

Mainland and island boundaries are specified as allowing tangential slip, and flow boundaries are forced with tidal constituents from the le Provost database (le Provost et al. 1998). The water level at the eastern flow boundary is also raised by $0.33 \mathrm{~m}$ to produce a steady, northwest-directed flow of $\sim 0.4 \mathrm{~m} / \mathrm{s}$ through the narrowest cross section of the strait (United Kingdom Hydrographic Office 2006; United States National Geospatial Intelligence Agency 2016). To validate the model, harmonic predictions of water levels and current velocities are obtained from the British Admiralty's TotalTide software for a number of locations within the domain (Fig. 1). Harmonic analysis of these datasets reveals five significant tidal constituents, but, to simplify calibration, only the largest of these, which are expected to contribute disproportionately to the available power (Garrett and Cummins 2005; Adcock et al. 2014), are used. The eastern and western flow boundaries are forced with M2 and S2 tides, the amplitudes of which are adjusted to improve the agreement between the water level results and the TotalTide predictions.

The drag on the flow due to bed roughness is given by $\mathbf{F}=\rho A_{b} \mathbf{u}|\mathbf{u}| C_{d}$, in which $\rho$ is the density of seawater, $A_{b}$ is the plan area of the seabed, $\mathbf{u}$ is the depth-averaged velocity vector, and $C_{d}$ is the seabed drag coefficient. In the present study, a spatially constant $C_{d}$ is used as a tuning parameter to fit the depth-averaged velocities to existing measurements. In reality, of course, the processes involved in seabed drag are much too complicated to describe with a single term (e.g. Soulsby 1997). Although it is a common assumption in this type of modelling, made for simplicity in the absence of field data, the assumption of a spatially constant $C_{d}$ introduces an additional source of uncertainty because it is unclear how the assumption of uniform bed roughness will effect the error between the estimated and actual maximum available power. In this case, a depth-dependent seabed drag coefficient of $C_{d}=0.0025$ is chosen and set to increase slowly 
Table 3 Predicted and modelled tidal ellipse major axis amplitudes $(\mathrm{m} / \mathrm{s})$

\begin{tabular}{lllllll}
\hline Station & M2 (predicted) & M2 (modelled) & Error $(\%)$ & S2 (predicted) & S2 (modelled) & Error $(\%)$ \\
\hline B1 & 0.214 & 0.128 & -67.2 & 0.135 & 0.076 & -77.9 \\
B2 & 0.295 & 0.503 & +41.4 & 0.188 & 0.211 & +10.9 \\
B3 & 0.410 & 0.611 & +32.9 & 0.211 & 0.295 & +28.5 \\
B4 & 0.529 & 0.504 & -5.0 & 0.267 & 0.282 & +5.3 \\
B5 & 0.639 & 0.580 & -10.2 & 0.306 & 0.350 & +12.6 \\
B6 & 0.442 & 0.228 & -93.9 & 0.249 & 0.076 & -227.2 \\
B7 & 0.592 & 0.594 & +0.3 & 0.288 & 0.252 & -14.3 \\
\hline
\end{tabular}

Table 4 Relative phases of predicted and modelled depth-averaged velocity signals (degrees)

\begin{tabular}{lllllll}
\hline Station & M2 (predicted) & M2 (modelled) & Error $\left(^{\circ}\right)$ & S2 (predicted) & S2 (modelled) & Error $\left(^{\circ}\right.$ ) \\
\hline B1-B2 & +47 & -21 & -68 & +48 & -66 & -114 \\
B2-B3 & -34 & -42 & -8 & -52 & -49 & +3 \\
B3-B4 & -46 & -35 & +11 & -46 & -34 & +12 \\
B4-B5 & -33 & -45 & -12 & +328 & +327 & -1 \\
B5-B6 & +304 & +311 & +7 & -51 & -79 & -28 \\
B6-B7 & -32 & -48 & -16 & -32 & -53 & -21 \\
\hline
\end{tabular}

(by a factor of $\left[1+(10 / d)^{10}\right]^{(1 / 30)}$ ) in depths $d<10$ m to help maintain model stability.

\subsection{Validation}

Before the turbines are inserted, the model is validated by comparing its water level and depth-averaged velocity results with the corresponding predictions from TotalTide. The model is allowed to spin up from still water conditions for 2 days before results from the following 31 days are recorded and harmonically analysed for comparison.

Tables 1, 2, 3 and 4 compare the amplitudes and relative phases of the predicted and modelled water level and depthaveraged velocity signals for the M2 and S2 tides. M2 water levels are found to agree quite well, albeit with errors in the order of $20 \%$ in the centre of the strait, while S2 levels agree less well, with particularly large errors near the western flow boundary. Tidal ellipses show poorer agreement, but depthaveraged velocities are nonetheless found to agree well with published co-tidal charts and sailing directions (Rizal and Sündermann 1994; United Kingdom Hydrographic Office 2006; Sindhu and Unnikrishnan 2013; United States National Geospatial Intelligence Agency 2016). Part of the disagreement between the model results and the TotalTide predictions may be due to a shift in the position of a nearby virtual amphidromic point (e.g. Rizal 2002), but, overall, the results are deemed satisfactory.

\subsection{Limitations}

Besides the obvious challenges involved in attempting to capture accurately a three-dimensional system with a two-

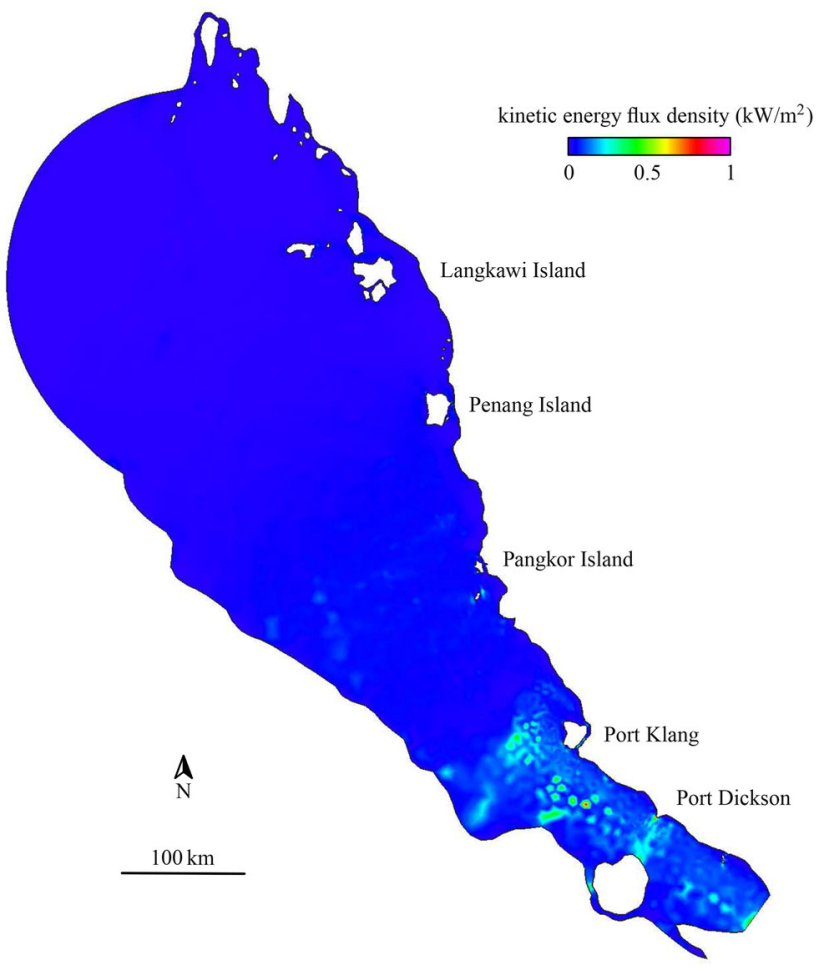

Fig. 2 (Online version in colour.) Model domain with contours of naturally occurring kinetic energy flux density, averaged over the 14.5 day spring-neap cycle

dimensional model, the lack of high quality source and validation data for this region means that the predictions of this model should be treated with caution. Despite its simplifying assumptions, however, the model appears to capture the dominant physics of the system reasonably well and so 
Fig. 3 Model domain and modified numerical mesh with close-up views of the five sites of interest. The positions of the turbine rows are marked with thick black lines

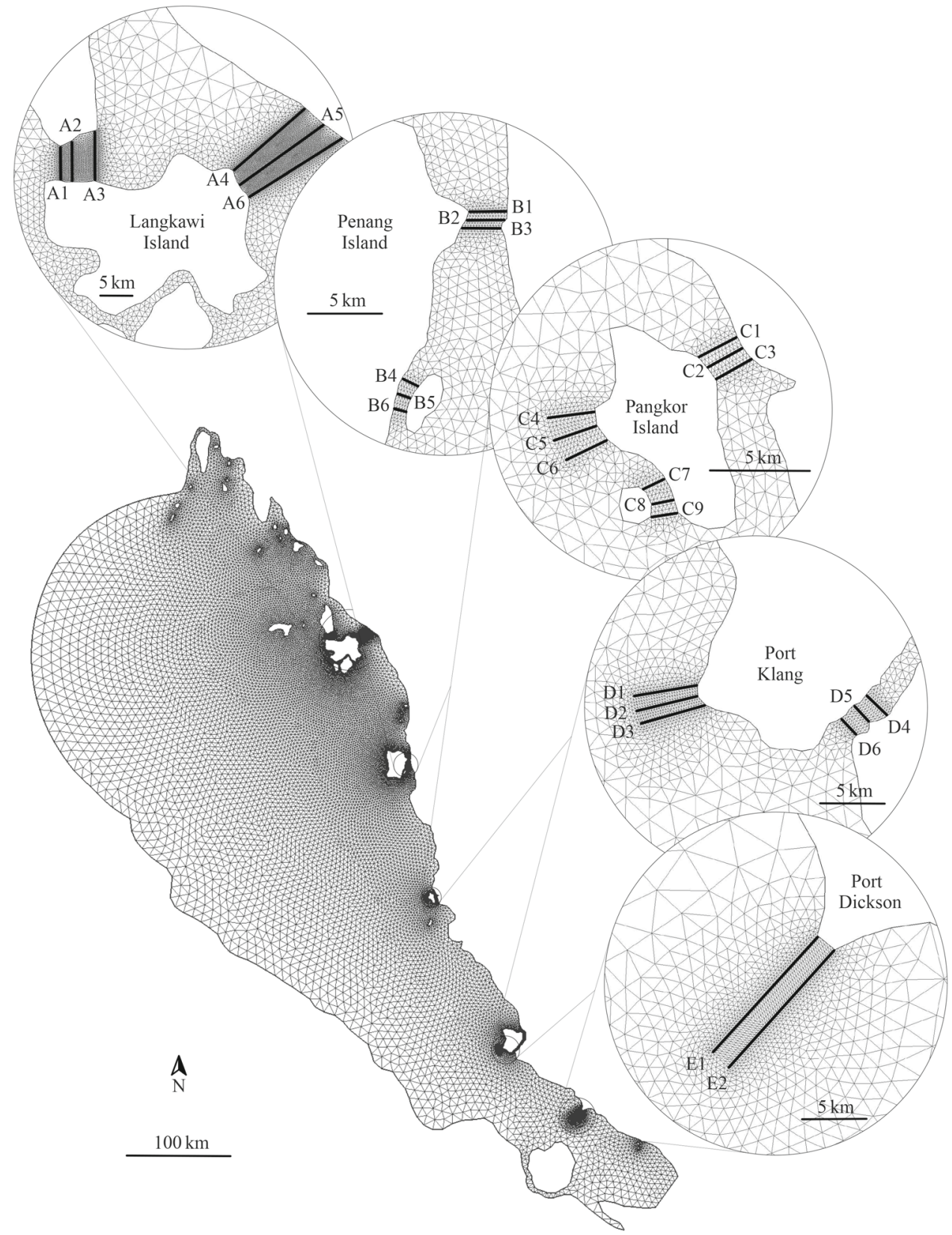

may be used to provide estimates of the maximum available power.

\section{Resource assessment}

Figure 2 shows a map of the naturally occurring kinetic energy flux density, which is a useful metric for demonstrating the spatial distribution of the tidal stream energy resource. The figure shows that although the kinetic energy flux density is generally low, there are a number of promising sites within the domain. For the present study, rows of tidal turbines are placed at five candidate sites along the Malaysian coastline:
Langkawi Island, Penang Island, Pangkor Island, Port Klang, and Port Dickson. These rows are placed strategically at the locations of highest kinetic energy flux, at which the mesh has been restructured and more finely resolved (Fig. 3).

For simplicity, the turbines within these rows are assigned identical local blockage ratios $B$ and local wake velocity coefficients $\alpha_{4}$. The wake velocity coefficients are kept constant in time because it is assumed that the additional amount of power that may be gained by varying the turbine resistance over daily (Vennell and Adcock 2014; Vennell 2016) or spring-neap cycles (Adcock et al. 2013) is relatively small. Local blockage ratios of 0.1 and 0.4 are chosen to represent moderately sized and very large developments, respectively, 
and different combinations of rows are considered. With the rows in place, the model is allowed to spin up for 2 days before results from the following 14.5 days are recorded for analysis. For each combination of rows, the model is run with three to four different wake velocity coefficients to determine by interpolation the maximum time-averaged available power.

Table 5 shows the maximum time-averaged power available to different combinations of rows of local blockage 0.4 . The results for rows of local blockage 0.1 are not shown (they have instead been made available online-see Sect. 5), because the available power is found to be quite low, even for the largest developments considered. Even if the highest upper bound estimate of $\sim 113 \mathrm{MW}$ could be generated continuously, the power produced would constitute only $\sim 0.85 \%$ of the growing Malaysian electricity demand (Malaysian Government Energy Commission 2016). It is clear, therefore, that the Malaysian tidal stream energy resource is not large enough to make a significant contribution to the country's energy mix. However, there may yet be opportunities to use low-speed tidal turbines, i.e. turbines with lower energy requirements (Lewis et al. 2015), in small-scale and off-grid electricity generation schemes.

The results presented in Table 5 show that there is very little interaction between the five sites, i.e. the amount of power available when turbines are placed at all five sites is only slightly less than the sum of the amounts available from each site. Weak interactions are to be expected, however, given the relative positions of the sites within the domain. The results also reveal a diminishing return on new rows at each site, i.e. the addition of a second and third row of turbines at a given location does not double and triple the available power. This well-known result is due to the fact that although adding rows to an array does increase its total power output, it also increases the resistance to flow through the array, thereby reducing the amount of power available to the turbines within it (Garrett and Cummins 2005; Vennell 2010). The sub-grid-scale actuator disc model also enables comparison, in terms of power per swept area, between different development options. In this case, the results reveal the most promising location for a row of tidal turbines to be Port Dickson, which is unsurprising, given its position within the narrowest section of the strait. The available power per swept area at Port Dickson is in fact found to be more than double that at the next best site, Port Klang.

\section{Practical considerations}

\subsection{Temporal variations in available power}

In assessing the energy resource, consideration of not only temporal averages, but also temporal variations is essen- tial because the way in which the available power varies over daily and spring-neap cycles will have important practical implications for the design and operation of turbine arrays (Adcock et al. 2013, 2014). One useful measure is the spring-neap power ratio, which compares the average power available on a typical day during spring tide to that on a typical day during neap tide. The final column in Table 5 presents the corresponding figures for each of the scenarios considered and reveals large variations over the spring-neap cycle, with power ratios ranging from 2.48 for one development at Port Klang to a remarkable 55.89 for another at Langkawi Island.

To further highlight the importance of these temporal variations, Fig. 4 presents examples from each of the five sites considered. The figure illustrates the variations of the normalised instantaneous available power $p$ over the length of the spring-neap cycle $T$ for each site, for scenarios in which all the rows at that site (and only that site) are in place and producing a near-peak time-averaged available power $\bar{p}$. Naturally, these variations are a function of site-specific tidal dynamics and row positioning, but it is interesting to note how different the variations are, particularly in terms of the tidal asymmetries, i.e. the inequalities between ebb and flood tides (Neill et al. 2014), and spring-neap power ratios (Adcock et al. 2014), given the relative proximity of the sites.

These plots also reveal other interesting features: that the power output at Langkawi Island does not drop to zero for an extended period of time, and that the envelopes of the tides at Port Klang and Port Dickson are not in phase with those at the other sites of interest. The former finding is likely due to the positioning of the turbine rows at locations of slightly different tidal phase, which results in a small amount of power being generated continuously as the tidal wave propagates around the island. The latter, which is not supported by the data from TotalTide, is likely a result of interactions between the waves entering from both ends of the domain, which are more pronounced in the shallow region near the eastern flow boundary. Although they do not alter the conclusions of the present study, phase differences such as these will be important if turbines are to be placed at multiple sites. It may even be possible to exploit the phase differences between sites to compensate, to a certain extent, for temporal variations and thereby produce a more regular power supply (e.g. Hardisty 2008; Iyer et al. 2013; Neill et al. 2016).

\subsection{Associated changes to the natural flow regime}

Assessing the viability of a candidate tidal energy site requires consideration of not only the available power, but also the practical aspects of marine energy development, which include management of technical and economic constraints, engagement with local stakeholders, and mitigation of adverse environmental impacts (e.g. Shields et al. 2011; 
Table 5 Power available to rows of very large turbines ( $B=0.4)$

\begin{tabular}{|c|c|c|c|c|c|}
\hline Site & Rows in place & Optimal $\alpha_{4}$ & $\begin{array}{l}\text { Maximum } \\
\text { time-averaged } \\
\text { available power }(\mathrm{MW})\end{array}$ & $\begin{array}{l}\text { Power per } \\
\text { swept area } \\
\left(\mathrm{kW} / \mathrm{m}^{2}\right)\end{array}$ & $\begin{array}{l}\text { Spring-neap } \\
\text { power ratio }\end{array}$ \\
\hline Langkawi & A1 & 0.357 & 2.913 & 8.792 & 55.89 \\
\hline \multirow[t]{8}{*}{ Island } & $\mathrm{A} 1 ; \mathrm{A} 2$ & 0.366 & 5.063 & 7.573 & 54.71 \\
\hline & $\mathrm{A} 1 ; \mathrm{A} 2 ; \mathrm{A} 3$ & 0.375 & 6.784 & 6.671 & 53.02 \\
\hline & A4 & 0.364 & 1.112 & 4.984 & 7.88 \\
\hline & A4; A5 & 0.380 & 1.760 & 4.182 & 6.85 \\
\hline & A4; A5; A6 & 0.385 & 2.087 & 3.163 & 6.25 \\
\hline & $\mathrm{A} 1 ; \mathrm{A} 4$ & 0.362 & 3.979 & 7.177 & 21.95 \\
\hline & $\mathrm{A} 1 ; \mathrm{A} 2 ; \mathrm{A} 4 ; \mathrm{A} 5$ & 0.373 & 6.702 & 6.152 & 20.75 \\
\hline & $\mathrm{A} 1 ; \mathrm{A} 2 ; \mathrm{A} 3 ; \mathrm{A} 4 ; \mathrm{A} 5 ; \mathrm{A} 6$ & 0.383 & 8.691 & 5.183 & 20.57 \\
\hline Penang & $\mathrm{B} 1$ & 0.366 & 1.452 & 18.928 & 9.12 \\
\hline \multirow[t]{8}{*}{ Island } & $\mathrm{B} 1 ; \mathrm{B} 2$ & 0.387 & 2.955 & 20.259 & 8.79 \\
\hline & B1; B2; B3 & 0.403 & 4.074 & 18.882 & 8.49 \\
\hline & B4 & 0.362 & 0.014 & 2.876 & 7.20 \\
\hline & B4; B5 & 0.364 & 0.051 & 4.556 & 6.97 \\
\hline & B4; B5; B6 & 0.396 & 0.091 & 4.858 & 6.79 \\
\hline & B1; B4 & 0.366 & 1.464 & 17.936 & 9.10 \\
\hline & B1; B2; B4; B5 & 0.387 & 2.991 & 19.046 & 8.74 \\
\hline & B1; B2; B3; B4; B5; B6 & 0.406 & 4.128 & 17.599 & 8.45 \\
\hline Pangkor & $\mathrm{C} 1$ & 0.368 & 0.345 & 9.425 & 9.43 \\
\hline \multirow[t]{11}{*}{ Island } & $\mathrm{C} 1 ; \mathrm{C} 2$ & 0.400 & 0.650 & 9.502 & 8.95 \\
\hline & $\mathrm{C} 1 ; \mathrm{C} 2 ; \mathrm{C} 3$ & 0.429 & 0.875 & 8.463 & 8.60 \\
\hline & $\mathrm{C} 4$ & 0.399 & 2.031 & 10.886 & 14.76 \\
\hline & $\mathrm{C} 4 ; \mathrm{C} 5$ & 0.442 & 3.340 & 8.121 & 13.66 \\
\hline & $\mathrm{C} 4 ; \mathrm{C} 5 ; \mathrm{C} 6$ & 0.479 & 4.104 & 6.843 & 12.94 \\
\hline & $\mathrm{C} 7$ & 0.414 & 0.130 & 2.003 & 12.90 \\
\hline & $\mathrm{C} 7 ; \mathrm{C} 8$ & 0.501 & 0.402 & 4.293 & 9.76 \\
\hline & $\mathrm{C} 7 ; \mathrm{C} 8 ; \mathrm{C} 9$ & 0.566 & 0.552 & 4.514 & 9.25 \\
\hline & $\mathrm{C} 1 ; \mathrm{C} 4 ; \mathrm{C} 7$ & 0.395 & 2.511 & 8.711 & 13.63 \\
\hline & $\mathrm{C} 1 ; \mathrm{C} 2 ; \mathrm{C} 4 ; \mathrm{C} 5 ; \mathrm{C} 7 ; \mathrm{C} 8$ & 0.441 & 4.365 & 7.612 & 12.27 \\
\hline & $\mathrm{C} 1 ; \mathrm{C} 2 ; \mathrm{C} 3 ; \mathrm{C} 4 ; \mathrm{C} 5 ; \mathrm{C} 6 ; \mathrm{C} 7 ; \mathrm{C} 8 ; \mathrm{C} 9$ & 0.479 & 5.450 & 6.603 & 11.56 \\
\hline Port & D1 & 0.392 & 6.358 & 25.664 & 3.78 \\
\hline \multirow[t]{8}{*}{ Klang } & D1; D2 & 0.428 & 11.350 & 22.110 & 3.87 \\
\hline & D1; D2; D3 & 0.453 & 15.110 & 19.069 & 3.90 \\
\hline & D4 & 0.388 & 0.595 & 15.213 & 2.48 \\
\hline & D4; D5 & 0.427 & 1.692 & 28.338 & 2.63 \\
\hline & D4; D5; D6 & 0.445 & 2.387 & 28.074 & 2.58 \\
\hline & D1; D4 & 0.391 & 6.962 & 24.273 & 3.63 \\
\hline & D1; D2; D4; D5 & 0.428 & 13.090 & 22.842 & 3.66 \\
\hline & D1; D2; D3; D4; D5; D6 & 0.450 & 17.580 & 20.037 & 3.66 \\
\hline Port & E1 & 0.388 & 47.390 & 67.769 & 3.69 \\
\hline \multirow[t]{2}{*}{ Dickson } & E2 & 0.380 & 42.620 & 56.637 & 3.70 \\
\hline & E1; E2 & 0.417 & 77.340 & 53.272 & 3.80 \\
\hline \multirow[t]{2}{*}{ All } & All rows (uniform tunings) & 0.422 & 112.600 & 22.227 & 4.40 \\
\hline & All rows (site-specific tunings) & Variable & 112.827 & 22.271 & 4.41 \\
\hline
\end{tabular}


Fig. 4 Normalised variations of available power $p$ and mean available power $\bar{p}$ over the 14.5 day spring-neap cycle
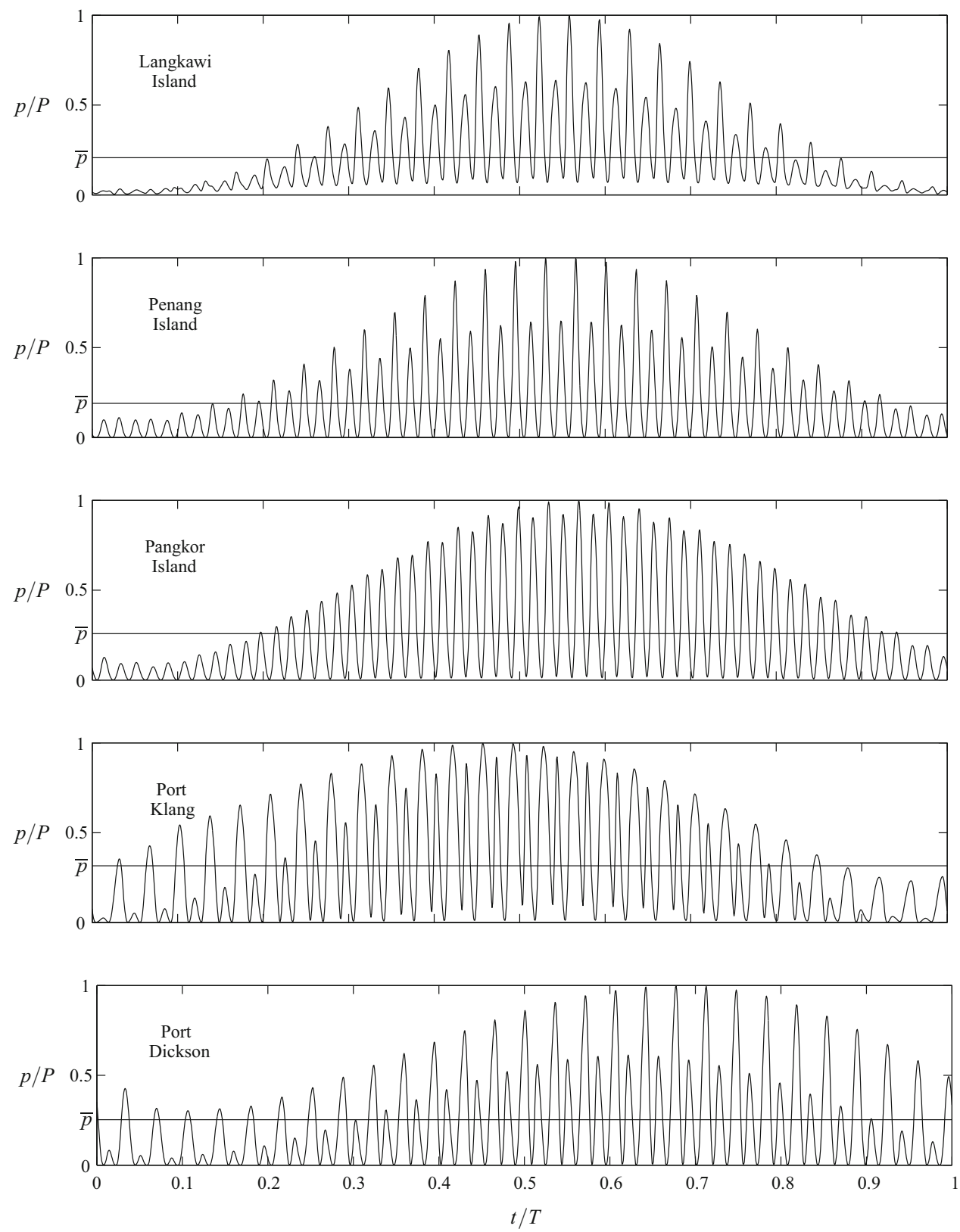

Bonar et al. 2015; Copping et al. 2016). Although a detailed analysis of these environmental impacts is beyond the scope of the present study, the line sink representation can be used to provide some insight into the associated changes to the natural flow regime. Figure 5 shows the predicted changes in depth-averaged velocity associated with near-peak available power production from two rows of very large $\left(B_{L}=0.4\right)$ turbines at Port Dickson, the most promising of the five sites considered. This snapshot, taken around the time of peak northwest-directed current, shows the turbine rows to slow the flow passing through them and accelerate the flow passing around them. Given that the peak unexploited velocities in the vicinity of Port Dickson are on the order of $1 \mathrm{~m} / \mathrm{s}$, the fig- ure suggests that the associated changes are not insignificant and may extend for several kilometres downstream of the turbines. It should be noted, however, that because depthaveraged models are unable to capture three-dimensional mixing processes, their ability to assess accurately the associated hydro-environmental impacts is limited.

\section{Conclusions}

Quirapas et al. (2015) outline the many challenges involved in developing marine renewable energy in Southeast Asia, the first and foremost of which is that of resource assessment. 


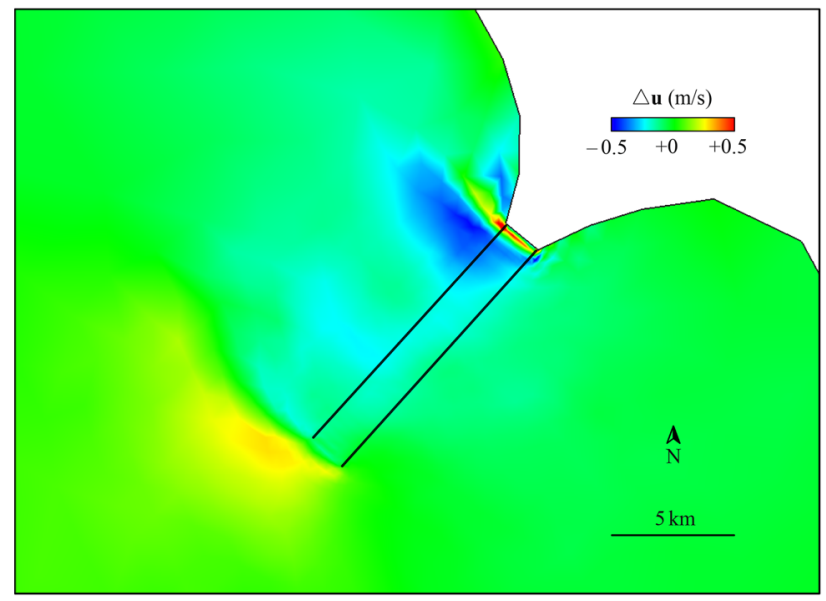

Fig. 5 (Online version in colour.) Predicted changes in depth-averaged velocity $\mathbf{u}(\mathrm{m} / \mathrm{s})$ associated with near-peak available power production from two rows of very large $\left(B_{L}=0.4\right)$ turbines at Port Dickson

The accurate assessment of a tidal stream energy resource is a complex and computationally expensive process, which requires careful numerical modelling to incorporate a broad range of external forces, from tidal constituents to surface waves (Hashemi et al. 2015; Hashemi and Lewis 2017); capture interactions between the turbines and the flow at numerous length and timescales (Adcock et al. 2015; Vennell et al. 2015); and account for three-dimensional flow characteristics including turbulence (Neill et al. 2014). The upper bound approach of Adcock et al. (2013) provides a simple and relatively inexpensive means by which to establish an upper bound on the power available to rows of turbines placed at a given location and also enables comparison, in terms of power per swept area, between different development options. This upper bound provides a useful first estimate of the tidal energy resource at a given location, which may also be used to assess whether or not this resource requires further investigation using more sophisticated modelling techniques.

The present study uses this upper bound approach to assess the tidal stream energy resources of a number of candidate sites in Malaysia. Results suggest that although the Malaysian tidal stream energy resource is not large enough to make a significant contribution to the country's energy mix, there may yet be opportunities to use low-speed tidal turbines in small-scale and off-grid electricity generation schemes.

To encourage the application of this simple, yet effective resource assessment methodology to other promising tidal energy sites, example input files and results from the model developed herein have been made available at https://ora.ox. ac.uk and the modified DG ADCIRC code of Serhadlioğlu (2014) has been made available upon request. It is hoped that this material will prove useful to the development of tidal stream power not only in Malaysia, but also worldwide.
Acknowledgements The authors gratefully acknowledge the support of the Engineering and Physical Sciences Research Council, which sponsored this work under the Global Challenges Research Fund. We thank Ahmad Firdaus, Dr. Dripta Sarkar, and Professor Alistair Borthwick for their assistance and the three anonymous reviewers for their helpful comments. We are especially grateful to Dr. Sena Serhadlıoğlu for kindly allowing us to share her modified DG ADCIRC code.

Open Access This article is distributed under the terms of the Creative Commons Attribution 4.0 International License (http://creativecomm ons.org/licenses/by/4.0/), which permits unrestricted use, distribution, and reproduction in any medium, provided you give appropriate credit to the original author(s) and the source, provide a link to the Creative Commons license, and indicate if changes were made.

\section{References}

Adcock TAA, Draper S, Houlsby GT, Borthwick AGL, Serhadlıoğlu S (2013) The available power from tidal stream turbines in the Pentland Firth. Proc R Soc A 469(2157):20130072. https://doi. org/10.1098/rspa.2013.0072

Adcock TAA, Draper S, Houlsby GT, Borthwick AGL, Serhadlığlu S (2014) Tidal stream power in the Pentland Firth-longterm variability, multiple constituents, and capacity factor. Proc Inst Mech Eng A 228(8):854-861. https://doi.org/10.1177/ 0957650914544347

Adcock TAA, Draper S, Nishino T (2015) Tidal power generationa review of hydrodynamic modelling. Proc Inst Mech Eng A 229(7):755-771. https://doi.org/10.1177/0957650915570349

Bohari ZH, Baharom MF, Jali MH, Sulaima MF, Bukhari WM (2016) Are tidal power generation suitable as the future generation for Malaysian climate and location: a technical review? Int J Appl Eng Res 11(10):7095-7099

Bonar PAJ, Bryden IG, Borthwick AGL (2015) Social and ecological impacts of marine energy development. Renew Sust Energ Rev 47:486-495. https://doi.org/10.1016/j.rser.2015.03.068

Chen H, Malanotte-Rizzoli P, Koh T-Y, Song G (2014) The relative importance of the wind-driven and tidal circulations in Malacca Strait. Cont Shelf Res 88:92-102. https://doi.org/10.1016/j.csr. 2014.07.012

Copping A, Sather N, Hanna L, Whiting J, Zydlewski G, Staines G, Gill A, Hutchison I, O’Hagan A, Simas T, Bald J, Sparling C, Wood J, Masden E (2016) Annex IV 2016 State of the science report: environmental effects of marine renewable energy development around the world. https://tethys.pnnl.gov/publications/stateof-the-science-2016. Accessed 22 Oct 2017

Divett T, Vennell R, Stevens C (2013) Optimization of multiple turbine arrays in a channel with tidally reversing flow by numerical modelling with adaptive mesh. Phil Trans R Soc A 371(1985):20120251. https://doi.org/10.1098/rsta.2012.0251

Draper S (2011) Tidal stream energy extraction in coastal basins, DPhil Thesis. University of Oxford, UK

Draper S, Houlsby GT, Oldfield MLG, Borthwick AGL (2010) Modelling tidal energy extraction in a depth-averaged coastal domain. IET Renew Pow Gener 4(6):545-554. https://doi.org/10.1049/ietrpg.2009.0196

Draper S, Stallard T, Stansby P, Way S, Adcock T (2013) Laboratory scale experiments and preliminary modelling to investigate basin scale tidal stream energy extraction. In: Proceedings of the 10th European Wave and Tidal Energy Conference (EWTEC), Aalborg, Denmark

Funke SW, Farrell PE, Piggott MD (2014) Tidal turbine array optimisation using the adjoint approach. Renew Energ 63:658-673. https:// doi.org/10.1016/j.renene.2013.09.031 
Garrett C, Cummins P (2005) The power potential of tidal currents in channels. Proc R Soc A 461:2563-2572. https://doi.org/10.1098/ rspa.2005.1494

Garrett C, Cummins P (2008) Limits to tidal current power. Renew Energy 33(11):2485-2490

Garrett C, Greenberg D (1977) Predicting changes in tidal regime: the open boundary problem. J Phys Oceanogr 7(2):171-181. https:// doi.org/10.1175/1520-0485(1977)007<0171:PCITRT>2.0.CO;2

Hardisty J (2008) Power intermittency, redundancy, and tidal phasing around the United Kingdom. Geogr J 174(1):76-84. https://doi. org/10.1111/j.1475-4959.2007.00263.x

Hashemi MR, Lewis M (2017) Wave-tide interactions in ocean renewable energy. In: Yang Z, Copping A (eds) Marine Renewable Energy. Springer, Cham, pp 137-158

Hashemi MR, Neill SP, Davies AG (2015) A coupled tide-wave model for the NW European shelf seas. Geophys Astrophys Fluid Dyn 109(3):234-253. https://doi.org/10.1080/03091929.2014.944909

Hassan HF, El-Shafie A, Karim OA (2012) Tidal current turbines glance at the past and look into future prospects in Malaysia. Renew Sust Energ Rev 16(8):5707-5717. https://doi.org/10.1016/j.rser.2012. 06.016

Houlsby GT, Draper S, Oldfield MLG (2008) Application of linear momentum actuator disc theory to open channel flow, Tech Rep OUEL 2296/08, Department of Engineering Science. University of Oxford, UK

Iyer AS, Couch SJ, Harrison GP, Wallace AR (2013) Variability and phasing of tidal current energy around the United Kingdom. Renew Energ 51:343-357. https://doi.org/10.1016/j.renene.2012.09.017

Kamaruzaman RM (1998) Navigational safety in the Strait of Malacca. Sing J Int'l Comp Law 2:468-485

Khalid N (2009) With a little help from my friends: maritime capacitybuilding measures in the Straits of Malacca. Contemp SE Asia 31(3):424-446

Kubatko EJ, Bunya S, Dawson C, Westerink JJ, Mirabito C (2009) A performance comparison of continuous and discontinuous finite element shallow water models. J Sci Comput 40(1):315-339. https://doi.org/10.1007/s10915-009-9268-2

Kubatko EJ, Westerink JJ, Dawson C (2006) hp discontinuous Galerkin methods for advection dominated problems in shallow water flow. Comput Method Appl Mech Eng 196(1):437-451. https://doi.org/ 10.1016/j.cma.2006.05.002

le Provost C, Lyard F, Molines JM, Genco ML, Rabilloud F (1998) A hydrodynamic ocean tide model improved by assimilating a satellite altimeter-derived data set. J Geophys Res 103:5513-5529. https://doi.org/10.1029/97JC01733

Lee KS, Seng LY (2009) Simulation studies on the electrical power potential harnessed by tidal current turbines. J Energy Environ 1(1): 18-23

Lewis M, Neill SP, Robins PE, Hashemi MR (2015) Resource assessment for future generations of tidal-stream energy arrays. Energy 83:403-415. https://doi.org/10.1016/j.energy.2015.02.038

Lim YS, Koh SL (2010) Analytical assessments on the potential of harnessing tidal currents for electricity generation in Malaysia. Renew Energy 35:1024-1032. https://doi.org/10.1016/j.renene.2009.10. 016

Low M (2012) Creating a balanced energy mix in Southeast Asia, Energy Studies Institute, National University of Singapore. http:// esi.nus.edu.sg/docs/default-source/default-document-library/ creating-a-balanced-energy-mix-in-southeast-asia-_-siew-2012. pdf. Accessed 22 Oct 2017

Malaysian Government Energy Commission (2016) Peninsular Malaysia Electricity Supply Outlook 2016. http://st.gov.my/index. $\mathrm{php} / \mathrm{en} / \mathrm{component} / \mathrm{k} 2 / \mathrm{item} / 680$-peninsular-malaysia-electricitysupply-industry-outlook-2016-download.html. Accessed 22 Oct 2017
Neill SP, Hashemi MR, Lewis MJ (2014) The role of tidal asymmetry in characterizing the tidal energy resource of Orkney. Renew Energy 68:337-350. https://doi.org/10.1016/j.renene.2014.01.052

Neill SP, Hashemi MR, Lewis MJ (2016) Tidal energy leasing and tidal phasing. Renew Energy 85:580-587. https://doi.org/10.1016/ j.renene.2015.07.016

Petinrin JO, Shaaban M (2015) Renewable energy for continuous energy sustainability in Malaysia. Renew Sust Energy Rev 50:967-981. https://doi.org/10.1016/j.rser.2015.04.146

Quirapas MAJR, Lin H, Abundo MLS, Brahim S, Santos D (2015) Ocean renewable energy in Southeast Asia: a review. Renew Sust Energy Rev 41:799-817. https://doi.org/10.1016/j.rser.2014.08. 016

Rizal S (2002) Taylor's problem-influences on the spatial distribution of real and virtual amphidromes. Cont Shelf Res 22:2147-2158. https://doi.org/10.1016/S0278-4343(02)00068-7

Rizal S, Damm P, Wahid MA, Sundermann J, Ilhamsyah Y, Iskandar T, Muhammad (2012) General circulation in the Malacca Strait and Andaman Sea: a numerical model study. Am J Environ Sci 8(5):479-488. https://doi.org/10.3844/ajessp.2012.479.488

Rizal S, Sündermann J (1994) On the M2 tide of the Malacca Strait: a numerical investigation. Ocean Dyn 46(1):61-80. https://doi.org/ 10.1007/BF02225741

Sakmani AS, Lam W-H, Hashim R, Chong H-Y (2013) Site selection for tidal turbine installation in the Strait of Malacca. Renew Sust Energy Rev 21:590-602. https://doi.org/10.1016/j.rser.2012. 12.050

Serhadlığlu S (2014) Tidal stream resource assessment of the Anglesey Skerries and the Bristol Channel, DPhil Thesis, University of Oxford, UK

Serhadlığlu S, Adcock TAA, Houlsby GT, Draper S, Borthwick AGL (2013) Tidal stream energy resource assessment of the Anglesey Skerries. Int J Mar Energy 3:e98-e111. https://doi.org/10.1016/j. ijome.2013.11.014

Shields MA, Woolf DK, Grist EPM, Kerr SA, Jackson AC, Harris RE, Bell MC, Beharie R, Want A, Osalusi E, Gibb SW, Side J (2011) Marine renewable energy: the ecological implications of altering the hydrodynamics of the marine environment. Ocean Coast Manag 54(1):2-9. https://doi.org/10.1016/j.ocecoaman.2010.10.036

Sindhu B, Unnikrishnan AS (2013) Characteristics of tides in the Bay of Bengal. Mar Geod 36(4):377-407. https://doi.org/10.1080/ 01490419.2013.781088

Soulsby RL (1997) Dynamics of marine sands: a manual for practical applications. Telford, London

United Kingdom Hydrographic Office (2006) Admiralty sailing directions (NP44): Malacca Strait and west coast of Sumatra pilot

United States National Geospatial Intelligence Agency (2016) Sailing directions (Pub 174): Strait of Malacca and Sumatera

Vennell R (2010) Tuning turbines in a tidal channel. J Fluid Mech 663:253-267. https://doi.org/10.1017/S0022112010003502

Vennell R, Funke SW, Draper S, Stevens C, Divett T (2015) Designing large arrays of tidal turbines: a synthesis and review. Renew Sust Energy Rev 41:454-472. https://doi.org/10.1016/j.rser.2014. 08.022

Vennell R, Adcock TAA (2014) Energy storage inherent in large tidal turbine farms. Proc R Soc A 470(2166):20130580. https://doi.org/ 10.1098/rspa.2013.0580

Vennell R (2016) An optimal tuning strategy for tidal turbines. Proc R Soc A 472(2195):20160047. https://doi.org/10.1098/rspa.2016. 0047

Wyrtki K (1961) Physical oceanography of the Southeast Asian waters. Scripps Institution of Oceanography, University of California, San Diego, CA 